\title{
Stress and Fear of Exposure to Sharps in Nurses
}

\author{
Malihe Sadat Moayed, ${ }^{1}$ Hosein Mahmoudi, ${ }^{2,}$ Abbas Ebadi, ${ }^{3}$ and Hamid Sharif $\mathrm{Nia}^{4}$ \\ ${ }^{1}$ Students' Research Committee, Nursing Faculty, Baqiyatallah University of Medical Sciences, Tehran, IR Iran \\ ${ }^{2}$ Trauma Research Center, Nursing Faculty, Baqiyatallah University of Medical Sciences, Tehran, IR Iran \\ ${ }^{3}$ Behavioral Science Research Center, Nursing Faculty, Baqiyatallah University of Medical Sciences, Tehran, IR Iran \\ ${ }^{4}$ School of Nursing and Midwifery of Amol, Mazandaran University of Medical Sciences, Sari, IR Iran \\ "Corresponding author: Hosein Mahmoudi, Trauma Research Center, Nursing Faculty, Baqiyatallah University of Medical Sciences, ,P.O. Box : 1956817173,Tehran, IR Iran. E-mail: \\ hmahmoudi@bmsu.ac.ir
}

Received 2015 August 09; Revised 2016 March 13; Accepted 2016 July 18.

\begin{abstract}
Background: Injuries caused by sharp objects, which involve biological hazards are considered as one of the most important factors that lead to stress among the nursing staff. Contact with sharp objects is a major concern among healthcare workers, especially nurses.

Objectives: This study was done to determine the amount of stress caused by exposure to sharp medical instruments among nurses. Materials and Methods: This was a cross-sectional research on 527 nurses, working at different medical centers across Iran, with a cluster-sampling method. The relevant data was collected with a valid and reliable questionnaire. The Cronbach's alpha coefficient of internal consistency of this instrument was 0.92 and interclass correlation coefficient was 0.94

Results: The results showed that ward satisfaction, having master of science, age, and number of contacts were significantly able to predict variance in stress scores. The adjusted line regression model explained $36 \%$ of the overall variance in stress score $(\mathrm{R} 2=0.60)$ Conclusions: The results of this study showed that exposure to sharp objects may cause high stress in the nursing staff. Considering higher levels of stress in the area of contact care, the provisions on how to deal with patients and safe care can help reduce stress.
\end{abstract}

Keywords: Injuries, Needle stick Injuries, Nurses, Occupational Injuries, Psychological, Stress

\section{Background}

Nowadays, with technological advances in medicine, the use of invasive procedures and injections in patients has expanded. As a result, health care staffs are exposed to a high risk of blood-borne pathogens (1). needle stick injury (NSI) is one of the most dangerous occupational situations (2). Among 20 types of blood-borne pathogens, which are transferred through NSI to health care workers, viral infections such as hepatitis $\mathrm{B}, \mathrm{C}$ and human immunodeficiency virus (HIV) are the most dangerous and common (3-5). Studies have shown that being exposed to infectious diseases and NSI can cause stress in nurses (6). This particular type of stress has a negative impact on the individuals and influences their families and colleagues (7).

Stress represents a major occupational hazard in modern age and has been incriminated for productivity reduction, absence from job, displacement of personnel, work conflicts and higher health care costs for employees (8). In a study on the psychological consequences of NSI, Greene and Griffiths found that the severity of the illness caused by needle stick is as significant as other psychological traumas. Moreover, the depression resulting from this situation is similar to other psychological traumas, and the duration of the condition is associated with the duration of obtaining the result of the second test. This has a farreaching impact on family relationships, sexual health and presence at the workplace (9). Between 1992 and 2003, Leigh et al. stated that injury stress led to the absence of 903 nurses, physicians and workers. Moreover, 7\% of the injuries resulted in loss of more than 31 working days (10). Naghavi et al. performed a study, which measured the incidence of post-traumatic stress disorder (PTSD) after injury, on doctors. Results showed that $12 \%$ were suffering from PTSD reactions, therefore suggesting an emphasis on addressing psychological reactions to NSI (11).

Despite numerous studies performed on the prevalence and incidence of injuries from sharp objects in Iran, no research with specific tools has been done concerning the stress caused by exposure to these objects.

\section{Objectives}

Therefore, the aim of this study was to assess the degree of stress in nurses, who have been exposed to sharp objects. 


\section{Materials and Methods}

The present analysis, performed in 2014, had a crosssectional design. The study subjects were nursing staff of several cities that were selected by cluster sampling in three stages. At first, four provinces were randomly chosen from different geographic areas of Iran. In the second stage, 11 hospitals of these cities were selected by the same form of simple randomization and finally, the nurses were enrolled through census sampling from every shift. Hospitals were located in Tehran (four hospitals), Isfahan (three hospitals), Kerman (two hospitals) and Hamedan (two hospitals.

Data collection was a two-part questionnaire including demographic characteristics and stress of exposure to sharps injury. The questionnaire section related to the stress of exposure to sharp injury contained 20 closed questions and the Likert response was classified to five scoring levels: very low (score of 1), low (score of 2), average (score of 3), high (score of 4), and very high (score of 5). The minimum total score that could be obtained was 20 and the maximum score was 100. The stress questionnaire had four dimensions, including safety policy (five questions), occupational safety (five questions), contact nursing (four questions) and mental-environmental conditions (six questions). This questionnaire was made by moayed et al. The Cronbach's alpha coefficient of internal consistency of this instrument was 0.92 and interclass correlation coefficient was $0.94(12,13)$. The questionnaire assessed stress levels caused by exposure to sharp objects in different situations or circumstances, as well as the amount of stress for nursing staff. In this study, the instrument content validity was used to validate the demographic characteristics. Inclusion criterion was having at least one-year experience at the current workplace. Based on the formula $\mathrm{n}=$ and $\mathrm{P}=0.3, \mathrm{~d}=0.04$, the sample size was calculated as 502, and considering the $10 \%$ loss, 550 questionnaires were distributed and 527 questionnaires were returned, thus a total of 527 fully completed questionnaires were included in the study.

The research objectives and the study methods were approved by the ethical committee of Baqiyatallah University of Medical Sciences, Teheran, Iran, and the study subjects gave their written consent.

The analyses were performed using SPSS 16.0 (released 2007; SPSS for Windows, SPSS Inc., Chicago, IL, USA). Basic descriptive statistics for quantitative variables was presented using mean (SD) and $\mathrm{n}(\%)$ for qualitative variables. Normality was examined with a Kolmogorov-Smirnov test. Adjusted linear regression model with 95\% Confidence Interval(CI) was used to predict the degree of stress in nurses, who were exposed to sharp objects. Statistical significance was set at $\mathrm{P}<0.05$.

\section{Results}

After review of the collected 527 questionnaires, the mean age of the study subjects was reported at 35.7 (SD = 8.7) years, and of these, $41.2 \%$ were male and $58.8 \%$ were female. The average work experience was $12(\mathrm{SD}=8.3)$ years, with a minimum of one year and maximum of 40 years.

Of the subjects, $83.1 \%$ had bachelor's degree and 58.3\% reported a history of injury with a sharp object. Stress from risk of injury by exposure to sharp objects in nurses was reported to be $58.37 \%$. The average stress score in nursing staff was 58.37 ( $S D=15.08,95 \% \mathrm{CI}: 57.08$ to 59.66 ).

Table 1 confirms that changes in independent variables were significantly able to predict variance in stress scores. The adjusted linear regression model explained 36\% of the overall variance in stress score $(\mathrm{R} 2=0.60)$, which was found to significantly predict outcome, $\mathrm{F}(4,521)=8.26, \mathrm{P}<$ 0.001 . According to Table 1 , the adjusted linear regression model showed risk predictors for stress score in nurses, who were exposed to sharp objects according to ward satisfaction, having Master of Science, age, and number of contacts.

The stress of nurses was measured based on different domains of the questionnaire after standardization (Figure 1).

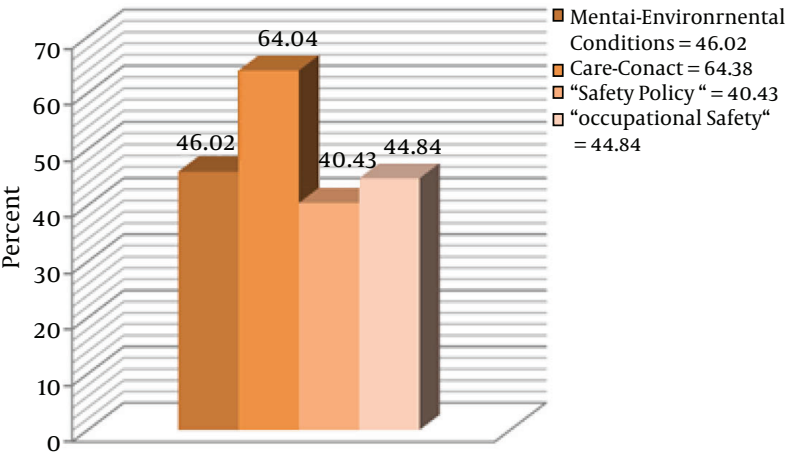

Figure 1. Stress in the Four Domains of the Questionnaire

\section{Discussion}

This study, using a proprietary questionnaire, was conducted to investigate the stress of dealing with sharp objects by nursing staff. Mean overall stress of exposure to sharp objects was $58.4 \pm 15.08 \%$. Regarding the occupational safety domain, one study showed a significant relationship between carelessness of nurses and injuries from 
Table 1. Predictors for Effective factors on the Level of Needle Stick Stress in Nurses

\begin{tabular}{|c|c|c|c|c|c|}
\hline Variables & No. $(\%)$ & Unadjusted, B (95\% CI) & $\mathbf{P}$ & Adjusted, B (95\% CI) & $\mathbf{P}$ \\
\hline \multicolumn{6}{|l|}{ Gender } \\
\hline Female & $310(58.8)$ & $-0.9(-3.53$ to 1.71$)$ & 0.49 & . & . \\
\hline Male & $217(41.2)$ & 1.0 & & 1.0 & \\
\hline \multicolumn{6}{|l|}{ Status of ward } \\
\hline Fix & $442(83.9)$ & 1.0 & & 1.0 & \\
\hline Variable & $85(16.1)$ & $0.22(-3.32$ to 3.77$)$ & 0.90 & . & \\
\hline \multicolumn{6}{|l|}{ Overtime } \\
\hline Yes & $397(75.3)$ & $2.03(-0.03$ to 4.11$)$ & 0.054 & - & \\
\hline No & $130(24.7)$ & 1.0 & & 1.0 & \\
\hline \multicolumn{6}{|l|}{ Job Satisfaction } \\
\hline Yes & $398(75.5)$ & $-3.61(-6.59$ to -0.63$)$ & .01 & - & \\
\hline No & $129(24.5)$ & 1.0 & & 1.0 & \\
\hline \multicolumn{6}{|l|}{ Ward satisfaction } \\
\hline Yes & $418(79.3)$ & $-4.79(-7.96$ to -1.63$)$ & 0.003 & $-4.05(-7.19$ to -0.96$)$ & 0.01 \\
\hline No & $109(20.7)$ & 1.0 & & 1.0 & \\
\hline \multicolumn{6}{|l|}{ Disease } \\
\hline Yes & $62(11.8)$ & $-0.45(-4.19$ to 3.28$)$ & 0.81 & - & - \\
\hline No & $465(88.2)$ & 1.0 & & 1.0 & \\
\hline \multicolumn{6}{|l|}{ History of contact } \\
\hline Yes & $307(58.3)$ & 3.79 (1.19 to 6.38$)$ & 0.41 & - & . \\
\hline No & $220(41.7)$ & 1.0 & & 1.0 & \\
\hline \multicolumn{6}{|l|}{ Education } \\
\hline Associate degree & $66(12.5)$ & 1.0 & & 1.0 & - \\
\hline Bachelor degree & $438(83.1)$ & $-3.15(-6.60$ to 0.30$)$ & 0.07 & - & \\
\hline Master of science & $23(4.4)$ & $9.13(2.72$ to 15.54$)$ & 0.005 & $10.26(3.95$ to 16.58$)$ & 0.001 \\
\hline \multicolumn{6}{|l|}{ Marital Status } \\
\hline Single & $118(22.4)$ & 1.0 & & 1.0 & - \\
\hline Married & $402(76.3)$ & $-1.83(-4.92$ to 1.22$)$ & 0.24 & - & \\
\hline Divorced & $7(1.3)$ & $-11.41(-32.4$ to 9.58$)$ & 0.28 & . & \\
\hline \multicolumn{6}{|l|}{ Shift } \\
\hline Morning & $135(25.6)$ & $-2.32(-5.27$ to 0.63$)$ & 0.12 & - & - \\
\hline Evening & $5(0.9)$ & 1.0 & & 1.0 & \\
\hline Night & $14(2.7)$ & $2.54(-5.48$ to 10.57$)$ & 0.53 & - & \\
\hline Evening and night & $60(11.4)$ & $-0.27(-4.34$ to 3.79$)$ & 0.89 & - & \\
\hline Morning, evening & $29(5.5)$ & $1.20(-1.38$ to 3.79$)$ & 0.36 & . & \\
\hline Circulating & $284(53.9)$ & $1.93(-3.72$ to 7.59$)$ & 0.50 & - & \\
\hline \multicolumn{6}{|l|}{ Age } \\
\hline $35.72(7.78)^{\mathrm{a}}$ & & $-0.17(-0.33$ to -0.004$)$ & 0.04 & $-0.20(-0.37$ to -0.04$)$ & 0.01 \\
\hline \multicolumn{6}{|l|}{ Work experience } \\
\hline $12.05(8.02)^{\mathrm{a}}$ & & $-0.07(-0.22$ to 0.08$)$ & 0.35 & . & . \\
\hline \multicolumn{6}{|l|}{ Number of contacts } \\
\hline $2.02(4.23)^{\mathrm{a}}$ & & $0.47(0.17$ to 0.77$)$ & 0.002 & $0.51(0.21$ to 0.81$)$ & 0.001 \\
\hline
\end{tabular}

${ }^{a}$ Mean (Standard Deviation).

sharp objects, especially in the setting of insufficient number of nurses (1.92 times), weariness and excitement (2.16 times), lack in resources support (1.88 times) and inexperience of nurses (1.74 times). Considering the actual conditions of a shortage of nurses, there is an increase of the degree and amount of damage secondary to injury (14). The amount of stress in the contact - care sector was 38.64\%. The study of Torshizi and Ahmadi measured the domain of patient care stress in nurses by using two items, exposure to body fluids and risk of infectious diseases transmission, which were insufficient for the evaluation of stress produced by sharp objects (15). The severity and extent of 
the stress of a contact - care study conducted on two nurses that were injured during care of an HIV patient, in addition to emotional problems during a 22-month follow up, led to depression, anxiety, insomnia and nightmares in the participants, even after receiving negative laboratory results about any possible infection (16).

Stress in the area of mental and environmental conditions was calculated as $46.02 \%$.

Each of the studies focused on only one of the items of the area. In the study of O'Connor, it was demonstrated that injury by sharp objects caused leave or absence and prolonged work interruption due to anxiety or stress disorder, with a rate of one out of 20 individuals, resulting in a reduction of the quality of work (17). The study of Seng et al. showed that only 146 cases out of 242 injured health workers reported their injuries to the authorities (4). Results of other studies showed that improvement in performance attitudes and increasing awareness and education are essential to control and reduce damage (18). The cause of damage is related to the workplace, including improper conditions for disposal of the needles and sharp instruments, overcrowding, noise, heat, chaos, lack or inadequate protective equipment gloves, goggles and gowns, which account for $27.2 \%$ and patient-related factors, such as sudden movements, improper use of equipment designed for patient and disease-related damage by sharp objects, which are responsible for $7.6 \%$ of the total causes (19).

In the area of safety policy, stress accounted for $43.40 \%$. Serinken et al. showed that personnel-related factors, including failure to use protective equipment, carelessness, lethargy, and lack of proper training, caused $64.9 \%$ of incidents (19). It is noteworthy to mention that only $36 \%$ of nurses, who were injured with needle stick within the past year, reported this to their supervisor or hospital emergency ward or infection control committee (20). Rampal et al. in Malaysia, showed a high level of awareness and knowledge of the universal precautions, however, there's still a gap between science and practice, which leads to the extended rate of damage (21). However, other results showed that health workers required more training (22). In another study, 38.3\% of the subjects had a history of injury from needles and sharp objects within the last six months (23). We calculated the incidence of injuries with sharp objects at $58.3 \%$, which is different to the study of Sharifian et al. because of the three-month period of investigation in their study, compared to our study, which was performed during a longer time period (24).

However, the results of a study in Germany showed a reduced incidence of NSI in nurses inclined to use a safety box. The use of safety equipment reduced the rate of such injuries from $69 \%$ to $52 \%$ (25). In our study, despite the fact that more than $75 \%$ of the participants worked more than the required time, there was no significant difference in the amount of stress.

However, a study in Baltimore confirmed that working for 13 hours or more during a day marked a significant contribution to the incidence of NSI (26).

The results of this study, showed that stress levels in nurses are highly increased by working with sharp objects, an issue, which requires special attention from authorities to implement educational programs and raise the awareness and ability of the staff to prevent injury and to improve the skills of self-control in stressful situations. Mastery over the mind, the environment and the health service is the best course, in addition, to ensure risk-free environments, providing facilities to reduce injuries and making managers understand their duties to follow up and provide medical service and prophylaxis in the event of injury, are necessary.

\section{Acknowledgments}

The authors would like to thank all those who participated in this study. This study is based on a research project of the faculty nursing of the Baqiyatallah University of Medical Sciences.

\section{Footnotes}

Authors' Contribution: Malihe Sadat Moayed conceived and designed the evaluation, collected the clinical data and analyzed them, and drafted the manuscript. Hosein Mahmoudi participated in designing the evaluation, supervised the drafting of the manuscript and revised it critically for important intellectual content. Abbas Ebadi and Hamid Sharif Nia had substantial contributions to analysis and interpretation of data, and revised it critically for important intellectual content. All authors read and approved the final manuscript.

Financial Disclosure: The author(s) declare no conflicts of interest with respect to the authorship and/or Publication of this article.

Funding/Support: No funding.

\section{References}

1. Aggarwal V, Seth A, Chandra J, Gupta R, Kumar P, Dutta AK. Oc cupational exposure to human immunodeficiency virus in health care providers: a retrospective analysis. Indian J Community Med. 2012;37(1):45-9. doi: 10.4103/0970-0218.94024. [PubMed: 22529540].

2. Gabriel J. Reducing needlestick and sharps injuries among healthcare workers. Nurs Stand. 2009;23(22):41-4. doi: 10.7748/ns2009.02.23.22.41.c6777. [PubMed: 19263961]. 
3. Ertem M, Dalar Y, Cevik U, Sahin H. Injury or body fluid splash incidence rate during three months period in elective surgery procedures, at Dicle University Hospital, Diyarbakir, Turkey. Ulus Travma Acil Cerrahi Derg. 2008;14(1):40-5. [PubMed:18306066].

4. Seng M, Lim JW, Sng J, Kong WY, Koh D. Incidence of needlestick injuries among medical students after implementation of preventive training. Singapore Med J. 2013;54(9):496-500. [PubMed: 24068057].

5. Quinn MM, Markkanen PK, Galligan CJ, Kriebel D, Chalupka SM, Kim H, et al. Sharps injuries and other blood and body fluid exposures among home health care nurses and aides. Am J Public Health. 2009;99 Suppl 3:S710-7. doi: 10.2105/AJPH.2008.150169. [PubMed: 19890177].

6. Sohn JW, Kim BG, Kim SH, Han C. Mental health of healthcare workers who experience needlestick and sharps injuries. J Occup Health. 2006;48(6):474-9. [PubMed: 17179640].

7. Gupta A, Anand S, Sastry J, Krisagar A, Basavaraj A, Bhat SM, et al. High risk for occupational exposure to HIV and utilization of postexposure prophylaxis in a teaching hospital in Pune, India. BMC Infect Dis. 2008;8:142. doi:10.1186/1471-2334-8-142. [PubMed:18939992].

8. Moustaka A, Constantinidis TC. Sources and effects of Work-related stress in nursing. Health Sci J. 2010;4(4).

9. Green B, Griffiths EC. Psychiatric consequences of needlestick injury. Occup Med (Lond). 2013;63(3):183-8. doi: 10.1093/occmed/kqt006. [PubMed: 23430785].

10. Leigh JP, Wiatrowski WJ, Gillen M, Steenland NK. Characteristics of persons and jobs with needlestick injuries in a national data set. Am J Infect Control. 2008;36(6):414-20. doi: 10.1016/j.ajic.2007.07.020. [PubMed: 18675147].

11. Naghavi SH, Shabestari O, Alcolado J. Post-traumatic stress disorder in trainee doctors with previous needlestick injuries. Occup Med (Lond). 2013;63(4):260-5. doi: 10.1093/occmed/kqt027. [PubMed: 23580567].

12. Moayed MS, Mahmoudi H, Ebadi A, Salary MM, Danial Z. Effect of Education on Stress of Exposure to Sharps Among Nurses in Emergency and Trauma Care Wards. Trauma Mon. 2015;20(2):17709. doi: 10.5812/traumamon.20(2)2015.17709. [PubMed: 26290853].

13. Moayed MS, Mahmoudi H, Ebadi A, Salari MM. Needlestick stress in nurses: A questionnaire development. Intl J Cur Life Sci. 2014;4(12):12865-70.

14. Clarke SP, Sloane DM, Aiken LH. Effects of hospital staffing and organizational climate on needlestick injuries to nurses. Am J Public Health. 2002;92(7):1115-9. [PubMed: 12084694].
15. Torshizi L, Ahmadi F. Job stressors from clinical nurses'perspective [in Persian]. Iran J Nurs. 2011;24(70):49-60.

16. Worthington MG, Ross JJ, Bergeron EK. Posttraumatic stress disorder after occupational HIV exposure: two cases and a literature review. Infect Control Hosp Epidemiol. 2006;27(2):215-7. doi: 10.1086/501155. [PubMed: 16465645].

17. O'Connor MB. The psychological impact of needlestick injuries. Ir J Med Sci. 2011;180(3):771. doi: 10.1007/s11845-011-0708-2. [PubMed: 21461641].

18. Saleem T, Khalid U, Ishaque S, Zafar A. Knowledge, attitudes and practices of medical students regarding needle stick injuries. J Pak Med Assoc. 2010;60(2):151-6. [PubMed: 20209710].

19. Serinken M, Karcioglu O, Kutlu SS, Sener S, Keysan MK. A survey of needlesticks and sharp instrument injuries in emergency health care in Turkey. I Emerg Nurs. 2009;35(3):205-10. doi: 10.1016/j.jen.2008.02.001. [PubMed:19446124].

20. Azadi A, Anoosheh M, Delpisheh A. Frequency and barriers of underreported needlestick injuries amongst Iranian nurses, a questionnaire survey. J Clin Nurs. 2011;20(3-4):488-93. doi: 10.1111/j.13652702.2010.03252.x. [PubMed: 20846246].

21. Rampal L, Zakaria R, Sook LW, Zain AM. Needle stick and sharps injuries and factors associated among health care workers in a Malaysian hospital. Eur J Soc Sci. 2010;13(3):354-62.

22. Mahfoozpour S, Baratloo A, Hatamabadi H, Karimian K, Safari S. Minding the Prevention Protocol for Blood-Borne Diseases via EM Residents. Trauma Mon. 2013;18(1):50-3. [PubMed: 3860654].

23. Adib-Hajbaghery M, Lotfi MS. Behavior of healthcare workers after injuries from sharp instruments. Trauma Mon. 2013;18(2):75-80. doi: 10.5812/traumamon.12779. [PubMed: 24350157].

24. Sharifian SA, Aminian O, Afsharisaleh L. Occupational stress and its relationship with need lestick injury among emergency department personnel [in Persian]. Occup Med. 2012;3(4):7-13.

25. Hoffmann C, Buchholz L, Schnitzler P. Reduction of needlestick injuries in healthcare personnel at a university hospital using safety devices. J Occup Med Toxicol. 2013;8(1):20. doi: 10.1186/1745-6673-8-20. [PubMed: 23895578].

26. Trinkoff AM, Le R, Geiger-Brown J, Lipscomb J. Work schedule, needle use, and needlestick injuries among registered nurses. Infect Control Hosp Epidemiol. 2007;28(2):156-64. doi: 10.1086/510785. [PubMed: 17265396]. 